\title{
Study Nutritional Status by Waist Circumference and Waist Hip Ratio
}

\section{Dr. Kankana DE*}

Research Scholar, Vidyasagar University, Medinipur, West Bengal 721102, India

\section{Introduction}

Anthropometric evaluation is essential feature for assigning nutritional status of Adolescent. To measure body composition mid upper arm circumference, body weight, height, skinfolds those measurements are most essential. Men and prone to heart disease when their waist circumference goes beyond $94 \mathrm{~cm}$ in men and $80 \mathrm{~cm}$ for women. This measurement is widely used in the classification of obesity. Waist to hip ratio can predict mortality. Changes in body composition and changing in every stage of life is reflected in measurement. The WHR has been used as an indicator or measure of health, and the risk of developing serious health conditions. WHR correlates with fertility (with different optimal values for males and females). WHR is used as a measurement of obesity, which in turn is a possible indicator of other more serious health conditions [1-5]. Receiver-Operating Characteristic (ROC) analysis is a very useful tool for central obesity and relation with waist-hip ratio and CED (Chronic Energy Deficiency).

WHR when goes above 80 in women and 1 in men is sign of health risk in men, this is cause due to excess fat deposition [6-8]. Waist circumference is tool to assessing abdominal fat and health status. For overweight $85^{\text {th }}$ percentile is threshold point of overweight and $95^{\text {th }}$ percentile is threshold of obesity.

\section{Materials and Methods}

\section{Area of study and sample size}

Subjects are adolescent girls aged 10-19 years. They belong to Salboni Block which is one of blocks of Paschim Medinipur, West Bengal.

Participants of socioeconomic data are collected through structured questionnaire, anthropometric data are collected through different instruments and cross section study is done on 1009 girls.

Height was measured to the nearest $0.1 \mathrm{~cm}$ by using a stadiometer (Holtain Ltd., Crymych, UK) when the subjects stood wearing socks and with their heads in the Frankfort horizontal plane. Weight was measured to the nearest $0.1 \mathrm{~kg}$ with an electronic portable scale (Secadelta, Model 707). BMI was calculated as weight (kg) divided by height $(\mathrm{m})$ squared [9-12]. A metal tape was used to measure the circumference of the buttocks. Waist circumference was measured at a level midway between the lowest rib and the crista iliaca superior. The measurement was carried out at the end of a normal expiration while the subject stood upright with feet together and arms hanging freely at the sides. Hip circumference was measured at the maximum point below the waist, without compressing the skin. WHR was calculated by dividing the waist measurement by the hip measurement.

Derivation of the ROC curves was based on a method by Obuchowski for continuous-scale gold standards. ROC analyses were performed in order to evaluate the general performance of the BMI, WC and WHR. The percentage of body fat was considered as the reference standard for the ROC curve analysis of BMI for girls.

WC and WHR were performed by employing a non-parametric approach, which was implemented in Statistical Packages for Social Sciences (SPSS) Two-sided $\mathrm{p}$ values were considered statistically significant at $\mathrm{p}<005$.

\section{Results}

In this study mean waist circumference is 78.32(6.32) and mean Hip circumference is $84.64(6.57)$. In late adolescent phase girls are found centrally obese. 827 girls in overall study are centrally obese (Tables 1-3). Table 4 represents that at age [13-15] girls are centrally obese, 90 girls centrally obese at age 15 years. 80 girls are under nutrient among 1009 girls.

\section{Discussion}

ROC curves to evaluate obesity from BMI, WC and WHR data. They also found that BMI and WC indices were suitable for diagnostic tests; however, WHR was less useful. This trend observed in our study is in line with that observed during previous investigations by the above mentioned authors.

Nutrient needs during adolescence are higher than at any other time in the lifecycle, and failure to consume a healthy balanced diet during this time can have adverse effects on young people's well-being, energy and health. In addition to the impact on growth and development, a poor diet during this life stage can cause a number of immediate health problems, such as being overweight and obese in the short-term.

\section{Conclusion}

Central obesity had significant effect on chronic heart disease, those girls have shown centrally obese in his study; they have chances to experience heart disease in future (Tables 1-5; Figure 1).

\begin{tabular}{|c|c|c|c|c|c|}
\hline Variables & Minimum & Maximum & Mean & Std. Deviation & Variance \\
\hline $\begin{array}{c}\text { Waist circumference } \\
(\mathrm{cm})\end{array}$ & 51.40 & 97.40 & 78.32 & 6.351 & 40.34 \\
\hline $\begin{array}{c}\text { Hip circumference } \\
(\mathrm{cm})\end{array}$ & 62.00 & 100.00 & 84.85 & 6.573 & 43.29 \\
\hline
\end{tabular}

Table 1: Descriptive Statistics represent waist and hip circumferences.

\begin{tabular}{|c|c|c|}
\hline Descriptive statistic & Waist hip ratio & Waist height ratio \\
\hline & 1009 & 1009 \\
\hline Mean & 0.92 & 0.51 \\
\hline Std. Deviation & 0.061 & 0.04 \\
\hline
\end{tabular}

Table 2: Represents mean and standard deviation of waist-hip ratio and waistheight ratio.

*Corresponding author: Kankana DE, Research Scholar, Vidyasaga University, Medinipur, West Bengal 721102, India, Tel: +919474714273; E-mail: dekankana@gmail.com

Received December 21, 2016; Accepted January 23, 2017; Published January 27,2017

Citation: Kankana DE (2017) Study Nutritional Status by Waist Circumference and Waist Hip Ratio. J Health Med Informat 8: 248. doi: 10.4172/2157-7420.1000248

Copyright: ๑ 2017 Kankana DE. This is an open-access article distributed under the terms of the Creative Commons Attribution License, which permits unrestricted use, distribution, and reproduction in any medium, provided the original author and source are credited. 
Citation: Kankana DE (2017) Study Nutritional Status by Waist Circumference and Waist Hip Ratio. J Health Med Informat 8: 248. doi: 10.4172/21577420.1000248

Page 2 of 2

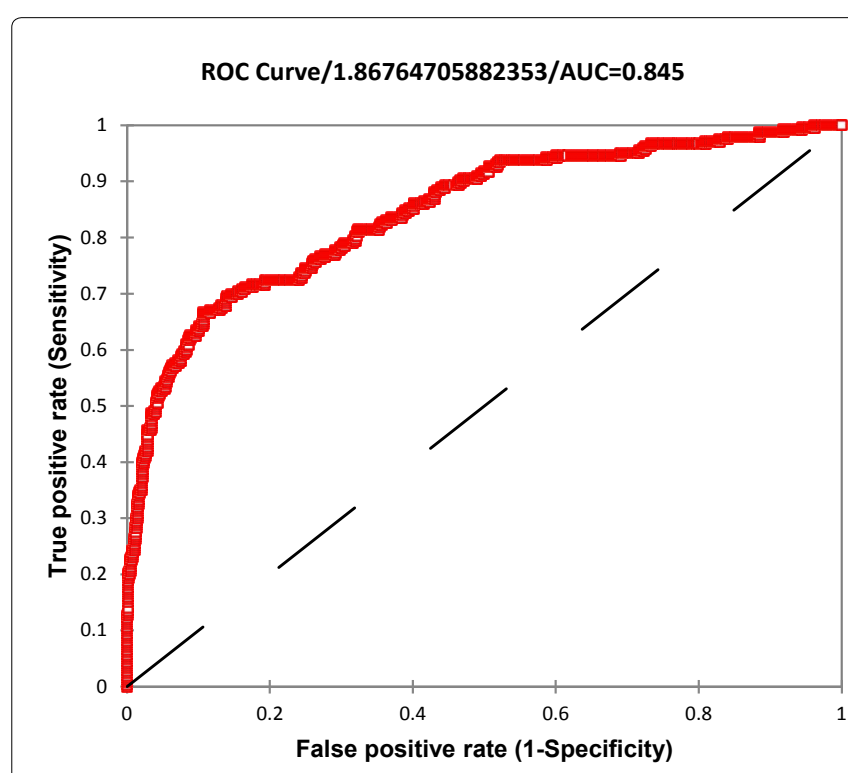

Figure 1: Roc curve represent relation of CED and waist-weight ratio.

\begin{tabular}{|c|c|c|c|}
\hline \multirow{2}{*}{ Age } & \multicolumn{2}{|c|}{ Waist circumference cut off } & \multirow{2}{*}{ Total } \\
\cline { 2 - 3 } & 1.00 & 2.00 & 100 \\
\hline 10 & 100 & 0 & 100 \\
\hline 11 & 100 & 0 & 100 \\
\hline 12 & 99 & 1 & 100 \\
\hline 13 & 98 & 2 & 100 \\
\hline 14 & 96 & 4 & 100 \\
\hline 15 & 89 & 11 & 100 \\
\hline 16 & 89 & 11 & 100 \\
\hline 17 & 85 & 15 & 100 \\
\hline 18 & 85 & 15 & 109 \\
\hline 19 & 92 & 17 & 1009 \\
\hline Total & 933 & 76 & \\
\hline
\end{tabular}

Table 3: Age wise present frequency of central obesity of studied girls

\begin{tabular}{|c|c|c|c|}
\hline \multirow{2}{*}{ Age(years) } & \multicolumn{2}{|c|}{ WHR cut off } & \multirow{2}{*}{ Total } \\
\cline { 2 - 3 } & $\mathbf{1 . 0 0}$ & $\mathbf{2 . 0 0}$ & 94 \\
\hline 10 & 20 & 74 & 91 \\
\hline 11 & 17 & 74 & 89 \\
\hline 12 & 19 & 70 & 99 \\
\hline 13 & 7 & 92 & 95 \\
\hline 14 & 13 & 82 & 94 \\
\hline 15 & 4 & 90 & 90 \\
\hline 16 & 4 & 86 & 92 \\
\hline 17 & 1 & 91 & 84 \\
\hline 18 & 7 & 77 & 98 \\
\hline 19 & 7 & 91 & 926 \\
\hline Total & 99 & 827 & \\
\hline
\end{tabular}

Table 4: Represents comparison of age wise waist-hip ratio. 1: Normal, 2: Centrally obese, WHR: Waist Hip Ratio.

\begin{tabular}{|c|c|c|c|c|c|c|}
\hline \multirow{2}{*}{ Age } & \multicolumn{7}{|c|}{ Different types of CED } & \multirow{2}{*}{ Total } \\
\cline { 2 - 7 } & $\mathbf{1 . 0 0}$ & $\mathbf{2 . 0 0}$ & $\mathbf{3 . 0 0}$ & $\mathbf{4 . 0 0}$ & $\mathbf{5 . 0 0}$ & \\
\hline 10 & 18 & 9 & 28 & 45 & 0 & 100 \\
\hline 11 & 9 & 8 & 18 & 64 & 1 & 100 \\
\hline 12 & 6 & 8 & 27 & 59 & 0 & 100 \\
\hline 13 & 2 & 8 & 25 & 65 & 0 & 100 \\
\hline 14 & 5 & 3 & 15 & 77 & 0 & 100 \\
\hline 15 & 1 & 2 & 16 & 80 & 1 & 100 \\
\hline 16 & 0 & 1 & 11 & 86 & 2 & 100 \\
\hline 17 & 0 & 0 & 7 & 93 & 0 & 100 \\
\hline 18 & 0 & 0 & 12 & 88 & 0 & 100 \\
\hline 19 & 0 & 0 & 5 & 104 & 0 & 109 \\
\hline Total & 41 & 39 & 164 & 761 & 4 & 1009 \\
\hline
\end{tabular}

\section{Acknowledgement}

At first I thankfully acknowledge to authorities of the Department of Anthropology, Vidyasagar University for providing me indispensable amenities, I convey my deep sense gratitude and earnest thanks to my Supervisor Prof Kaushik Sankar Bose for his pleasant guidance and careful assistance I thankfully acknowledge to clients of Anwesha Clinic for open handed support and cooperation during field Survey. I also express my loving thankfulness to all Adolescent girls who participated in research survey.

\section{References}

1. Kavak V, Pilmane M, Kazoka D (2014) Body Mmss index, waist circumference and waist-to-hip-ratio in the prediction of obesity in Turkish teenagers. Coll Antropol pp: 445-451.

2. Pan S, Yang YN, Ma X, Li XM, Chen Y (2014) Optimal cutoff of the waist-tohip ratio for detecting cardiovascular risk factors among Han adults in Xinjiang BMC. Cardiov Dis 14: 93

3. Lee CM, Huxley RR, Wildman RP, Woodward M (2008) Indices of abdominal obesity are better discriminators of cardiovascular risk factors than BMI: a meta-analysis. J Clin Epidemiol 61: 646-653.

4. Skrzypczak M, Szwed A, Chmara RP, Skrzypulec V (2007) Assessment of the $\mathrm{BMI}, \mathrm{WHR}$ and W/Ht in pre- and postmenopausal women. Anthropol Rev 70: 3-13.

5. De K (2016) Physical Growth and Relation of Menarche with Anthropometry Anthropol 4: 172

6. Bisai S, Bose K, Ghosh D, De K (2011) Growth pattern and prevalence of underweight and stunting among rural adolescents. J Nepal Paedtr Soc 31: 1.

7. De K, Das S, Bose K, Chakraborty R (2013) Nutritional Status Of Rural Girls Aged 10-18 Years Of Salboni, Paschim Medinipur, West Bengal, India. J Bio Sci Lif Sci.

8. Kankana D (2016) Influence of socio-economic status on nutritional status on rural adolescent girls. Anthropol 4: 168.

9. De K (2016) Assessment of Nutritional Status of Adolescent Girls by Mid-Upper Arm Circumferences of Paschim Medinipur, India. Prima Hea Ca 6: 242.

10. De K (2016) A Comparative Study on Nutritional Status of Adolescents Girls of Different Rural Area of West Bengal. Anthropol 4: 173.

11. De K (2017) Anthropometric status of Rural girl in India Journal Traditional and clinical naturopathy 6:205

12. Obuchowski NA (2015) An ROC-type measure of diagnostic accuracy when the gold standard is continuous-scale. Stat Med 25: 3.

13. Millar SR, Perry IJ, Broeckand JV, Phillips CM (2015) Optimal Central Obesity Measurement Site for Assessing Cardiometabolic and Type 2 Diabetes Risk in Middle-Aged Adults. PLoS One 10: 6

14. Peixoto MDRG, Benício MHDA, Latorre MDRDOL, PCBV (2006) Waist circumference and body mass index as predictors of hypertension. Arq Bras Cardiol 87: 4

15. http://apps.who.int/iris/bitstream/10665/44583/1/9789241501491 eng pdfhttp:/whqlibdoc.who.int/publications/2011/9789241501491_eng.pdf 